\title{
Analysis of Rainfall and Temperature Variations between 1956 and 2016 for Papua New Guinea
}

\author{
Nathan Sapala, Yuanyuan Cheng*, Dapeng $\mathbf{~ L i}^{*}$ \\ School of Environmental Science and Engineering, Suzhou University of Science and Technology, Suzhou, China \\ Email: sapalanathan@gmail.com, ${ }^{*}$ chengyy127@hotmail.com, *ustsldp@163.com
}

How to cite this paper: Sapala, N., Cheng, Y. Y., \& Li, D. P. (2021). Analysis of Rainfall and Temperature Variations between 1956 and 2016 for Papua New Guinea. Journal of Geoscience and Environment Protection, 9, 66-85.

https://doi.org/10.4236/gep.2021.96004

Received: June 1, 2021

Accepted: June 15, 2021

Published: June 18, 2021

Copyright $\odot 2021$ by author(s) and Scientific Research Publishing Inc. This work is licensed under the Creative Commons Attribution International License (CC BY 4.0).

http://creativecommons.org/licenses/by/4.0/

\begin{abstract}
The aim of the research was to assess the trend and variations in rainfall and temperature in Papua New Guinea between 1956 and 2016 (60 years) and project the trends from 2017 to 2047 (30 years). Meteorological data obtained from the World Bank Climate Database Headquarters in Washington, United States, from 1956 to 2016 were used in the models. The general linear model analysis was used to investigate the trend in both rainfall and temperature and to predict the future trends. Over the period of study period, 1956 to 2016, the study found that the climatic factors, rainfall and temperature pattern in Papua New Guinea have been changing. It was found that there is an increasing trend in rainfall and temperature. Projections revealed a further increase in rainfall and temperature into the future. Rainfall in Papua New Guinea has been increasing. The projection revealed that rainfall was trending upward with a linear model equation: Rainfall $=0.0093 x+252.38$. The increased trend in rainfall suggests that there is an increased trend in evaporation and transpiration. For temperature, although it does not come down to zero and to negative at nights or go up to $40^{\circ} \mathrm{C}$ or $50^{\circ} \mathrm{C}$ during the day time as in other countries, the change is clear in the analysis made in the study that there is an increasing trend. If nothing is done to combat the current rate of climate change in the country, the increasing trend in rainfall and temperature would continue. This calls for immediate actions as the issue needs to be addressed in time. Therefore, it is recommended that the government of Papua New Guinea consider incorporating climate change policies into their development plans.
\end{abstract}

\section{Keywords}

Rainfall, Temperature, Climate Change, Papua New Guinea 


\section{Introduction}

Climate change is the greatest threat to global health in the 21 st century (WHO, 2015). Changes in climate are already affecting species' distribution patterns (Cámara-Leret et al., 2019). No level of ecosystem restoration would offset the impacts of climate change where global average temperatures would increase by $3^{\circ} \mathrm{C}$ to $6^{\circ} \mathrm{C}$ by 2100 (CSIRO, 2015). Studies show that increase in rainfall is due linked to climate change. Rainfall extremes are increasing around the world, and the increase is linked to the warming of the atmosphere, due to climate change, which has taken place since pre-industrial times (Seth, 2013).

Papua New Guinea (PNG), one of the 10 most affected countries by climate change, is already feeling the effect of climate change (Sungkuk \& Ibrahim, 2015). A remote-sensing study showed that shoreline changes on Takú Atoll were remarkably variable with respect to both spatial and temporal dimensions. Long-term analyses of planform shoreline configurations, net changes in island area and the spatial variability of significant shoreline change rates from 1943 to 2012 indicated a trend towards island accretion (Mann \& Westphal, 2016).

A joint study made by the Pacific Climate Change Science Program (PCCSP), Commonwealth Scientific and Industrial Research Organisation (CSIRO) and the Papua New Guinea national weather services (NWS) revealed that the sea-level rise near Papua New Guinea measured by satellite altimeters (1993-2016) is about $7 \mathrm{~mm}$ per year (Kaluwin, Inape, \& Virobo, 2016). The joint study also reveals that warming trends are evident in both annual and seasonal mean air temperatures in the capital of PNG (at Port Moresby) for the period 1950-2009. These trends are considerably stronger in minimum air temperatures when compared to maximum air temperatures (Kaluwin et al., 2016).

PNG is already home to the world's first climate change refugees from its Carteret atolls in its Bougainville Island Province (IOM, 2008).

The specific objectives of this paper are as follows:

1) To examine the trends in rainfall and temperature in Papua New Guinea (1956-2016),

2) To investigate the variation in rainfall and temperature in Papua New Guinea (1956-2016), and

3) To make 30-year projections of rainfall and temperature for Papua New Guinea.

In order to achieve the objectives, the hypothesis that there is no change in temperature and rainfall variability in Papua New Guinea was tested.

\section{Research Methodology}

\subsection{Study Area}

Papua New Guinea is a country in Oceania, located on the northern tip of Australia, at latitude between $2^{\circ}$ to $11.3^{\circ}$ south and longitude between $141^{\circ}$ to $157.2^{\circ}$ east. It has two major international boundaries with the West Papua Province of Indonesia to the West and Australia to the South. The other international land 
boarders include Solomon Island, Vanuatu, and Fiji all to the South-east. Figure 1 shows the map of Papua New Guinea and its provinces where the rainfall and temperature data used in this work have been collected.

The country (shown in Figure 1) covers a total land area of 46.9 million hectors (CCDA, 2018). PNG has one of the biggest tropical forest in the world. Its forest covers $80 \%$ of the country's land area (CCDA, 2017). PNG's second national communication (SNC) to the UNFCCC states that the main climate drivers are the El Niño Southern Oscillation (ENSO) and, to a lesser extent, the position of the South Pacific Convergence Zone (SPCZ). ENSO has less influence in the northern part of the country (OCCD, 2014). The report further states that there are variations in annual average maximum and minimum temperatures.

The country has a wet season from November-April and a dry season form May-Oct. But rainfall seasonality is rather weak except for the region around Port Moresby (OCCD, 2014). The country has a tropical climate where it's monthly rainfall ranges from $250 \mathrm{~mm}-350 \mathrm{~mm}$ with average monthly temperature ranging from $26^{\circ} \mathrm{C}-28^{\circ} \mathrm{C}(\mathrm{CCDA}, 2018)$. A joint study made by the Pacific Climate Change Science Program (PCCSP), Commonwealth Scientific and Industrial Research Organisation (CSIRO) and the Papua New Guinea national weather services (NWS) shows that rainfall in Papua New Guinea is influenced by the West Pacific Monsoon (Kaluwin et al., 2016). The joint study shows that high year-to-year variability in rainfall is mostly due to the impact of the El Niño-Southern Oscillation (ENSO).

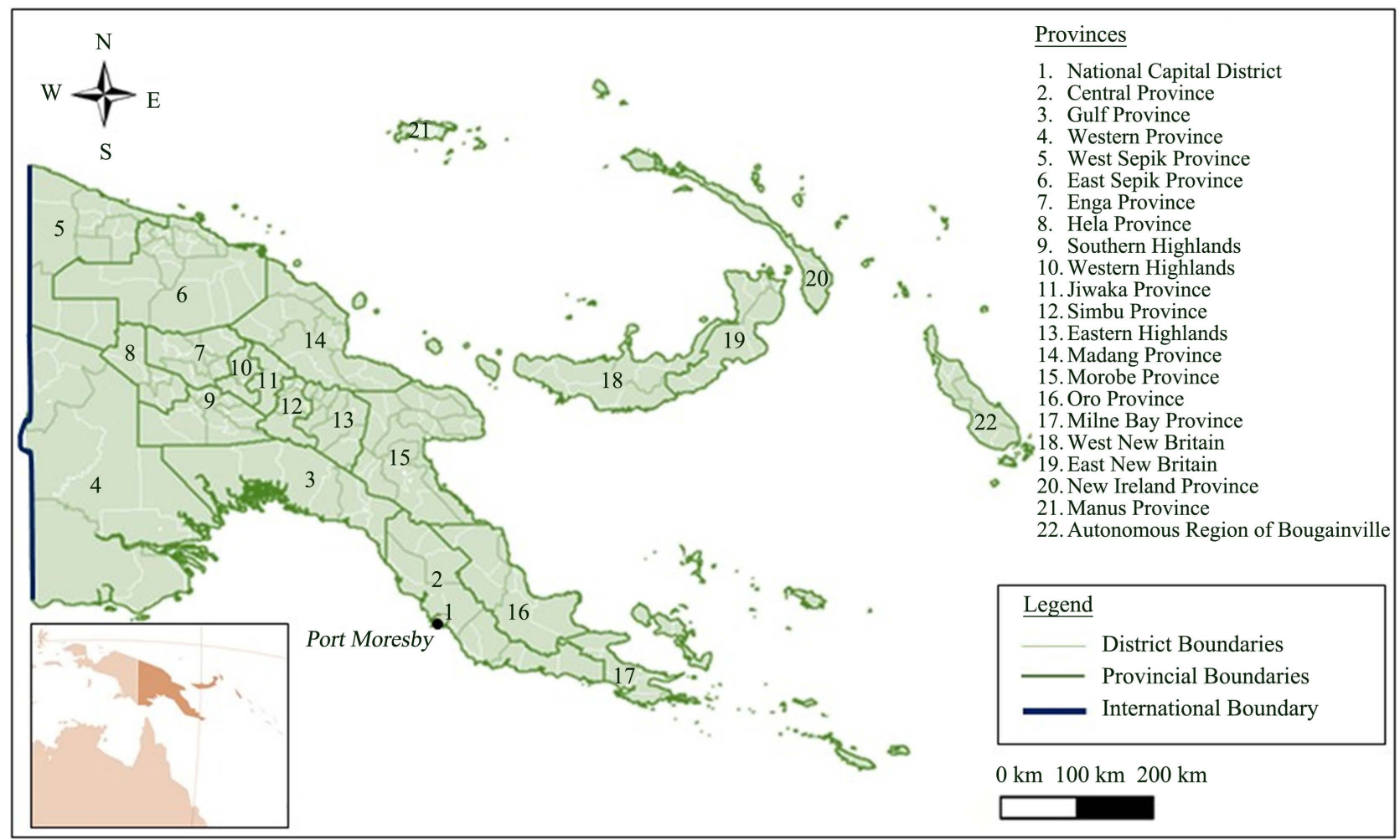

Figure 1. Map of Papua New Guinea with its 22 provinces. 
Most people in PNG are subsistence agriculturalists; they grow crops (or gather them from the forest) like tubers, fruits and nuts. The majority of the cropping is from fallow systems. Fallow systems involve clearing and cutting forest, some burning of felled vegetation, cultivation of crops for a number of years ( 3 - 5 years in the lowlands to continuous in the highlands) and then abandon the site to the natural process of regeneration (OCCD, 2014).

Agriculture has been the economic backbone of PNG and will continue to be so for a long time. PNG exports coffee, cocoa, copra, sugar, vanilla, and tea. Agricultural growth however has been only around 1\% the past decade (OCCD, 2014). With a population growth of around $2.7 \%$, it is clear that many rural families have had a negative income growth. Because of higher prices on the international markets for agricultural commodities the situation has improved a little recently (OCCD, 2014).

\subsection{Data Source}

Meteorological data of all weather stations in Papua New Guinea from 1956 to 2016 were obtained from the World Bank Climate Change Office in Washington D.C., United States. Monthly average rainfall and monthly temperature data were provided for the years 1956 to 2016. Data for 2017 to 2020 were unavailable for this work, because they were not provided, as those were not approved for the public to use. Those data will be available in September, 2021. All monthly data from January 1956 to December 2016 were provided, so there were no missing data in between. As such, no estimations were made to come up with any monthly data for the years 60 years, 1956 to 2016.

\subsection{Research Method}

Monthly average rainfall data for the twelve months were added then divided by twelve to come up with the average yearly rainfall for the country. The same was done for temperature, monthly average temperature data for the twelve months were added then divided by twelve to come up with the average yearly temperature for the country.

Excel spread sheet was used for the calculation of the yearly average rainfalls and temperatures, as this is an effective way to do calculations where minimal or no errors can be made in the calculations. Since the increase and decrease in both the yearly rainfalls and temperatures were the important elements to observe, linear forecast was used to observe the increasing trends. The linear forecast was made using excel spread sheet also because, as in the calculations, it is effective and errors can be minimal or none.

To estimate the rainfall and temperature for the next thirty years (2016-2047), the linear function $y=a+b x$ model was used. This model is an effective model used in many works to estimate future trendlines. This model was also used to determine linear regression trend and 5-year moving average line to the seasonal and annual rainfall data series for Lake Tana basin (LTB) area in Ethiopia (Weldegerima et al., 2018). Papua New Guinea used this model to estimate its car- 
bon-dioxide emission trendline for 2014-2018 in its forest reference level (FRL) to the United Nations Framework Convention on Climate Change (CCDA, 2017). (Panda \& Sahu, 2019) used this model to determine the trend of seasonal minimum temperature from 1980 to 2017. For this work, first of all, the slope and the intercept were calculated. To calculate the slope and the intercept, the following equations were used.

Equation I is the main equation used for the calculation of the projected data. Equation II and III are used to determine "b" and "a" respectively in Equation I. Equations IV, V, and VI are used to determine the values in Equation III. With the results of slope and intercept on hand, each was substituted for "b" and "a" respectively, while the already available monthly rainfall/temperature data were substituted for $x$.

Projected Rainfall $\left(P_{R}\right)$

$y=a+b x$

$P_{R}=$ intercept + slope $\times$ rainfall data

Projected Temperature $\left(P_{T}\right)$

$y=a+b x$

$P_{T}=$ intercept + slope $\times$ temperature data

The data used were monthly average rainfall and monthly average temperature. Using the monthly average temperature and monthly average rainfall, the yearly average rainfall and yearly average temperature were calculated. To calculate the yearly average rainfall and yearly average temperature, the arithmetic average methodology was used. The methodology is shown below.

$$
\operatorname{Arithmetic~mean}(\bar{x})=\frac{x_{1}+x_{2}+x_{3}+x_{4}+x_{5}+x_{6}+\cdots+x_{n}}{n}=\frac{\sum_{i=1}^{n} x_{i}}{n}
$$

Equation VII Arithmetic Average Methodology for projected rainfall and temperate data calculation

The yearly average rainfall and temperature results were used to observe the annual changes in rainfall and temperature and their trends after the calculations were made. Trendlines were also drawn using the calculated data as historical data.

\section{Results}

\subsection{Analysis of Rainfall and Its Trendline}

\subsubsection{Analysis of Monthly Rainfall for the Initial and the Final Year}

The average monthly rainfall for the initial year (1956) and the final year (2016) were selected to display to observe the difference in the amount of rainfall received and rainfall pattern in each of the months in the two years, after 60 years apart. Table 1 below shows the values and Figure 2 presents two graphs ("a" and "b") representing the two years.

Table 1 shows the recorded monthly rainfall for the initial year (1956) and the final year (2016) considered for this study. The two years were selected to observe the difference in the amount of rain received in each of the months after 60 years apart, before looking into the other years that are in between them. 


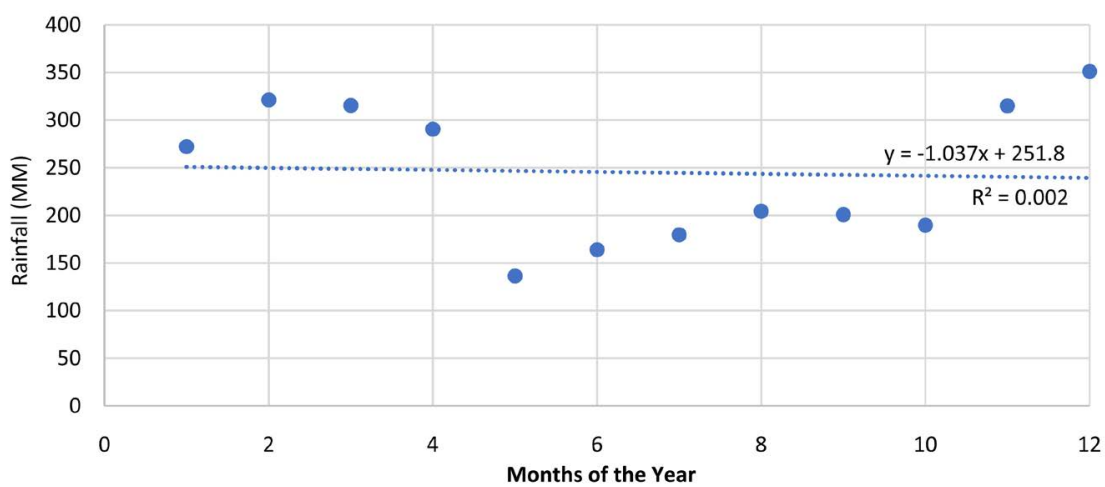

(a)

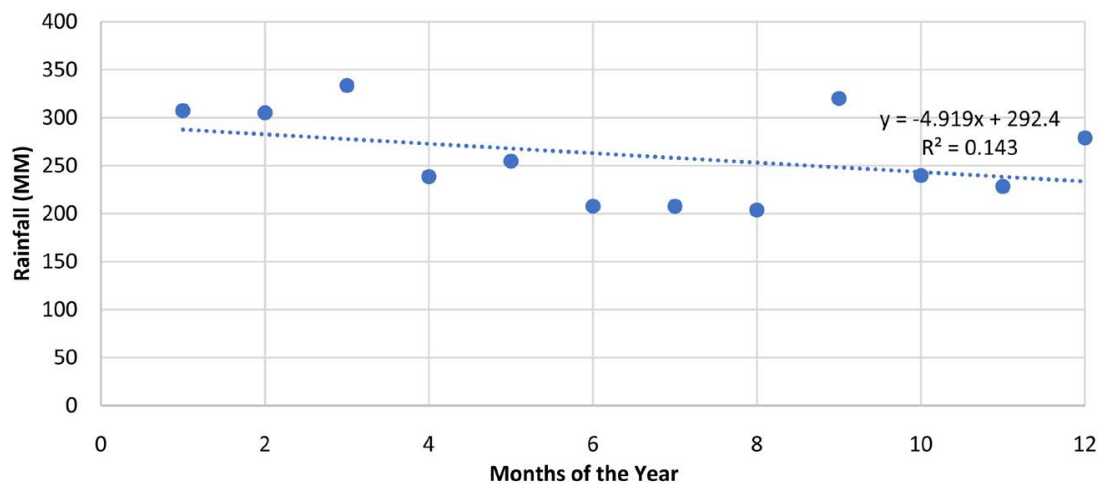

(b)

Figure 2. Above shows the monthly rainfall for Papua New Guinea for (a) 1956 initial year considered and (b) 2016, the final year considered for this research.

Table 1. Monthly rainfall statistics for the year 1956 and 2016.

\begin{tabular}{ccc}
\hline Months & Rainfall $(\mathrm{mm}), \mathbf{1 9 5 6}$ & Rainfall $(\mathrm{mm}), \mathbf{2 0 1 6}$ \\
\hline Jan & 272.255 & 307.243 \\
Feb & 321.284 & 305.243 \\
Mar & 315.291 & 333.609 \\
Apr & 290.636 & 238.417 \\
May & 136.472 & 254.757 \\
Jun & 163.996 & 207.825 \\
Jul & 179.753 & 207.551 \\
Aug & 204.26 & 203.823 \\
Sep & 200.765 & 320.095 \\
Oct & 189.765 & 239.805 \\
Nov & 315.069 & 228.207 \\
Dec & 351.188 & 278.85 \\
\hline
\end{tabular}

The lowest amount of monthly rainfall received in 1956 was $136.472 \mathrm{~mm}$ in the month of May, and the highest was $351.188 \mathrm{~mm}$ in the month of December. While in 2016, the lowest amount of monthly rainfall is $203.823 \mathrm{~mm}$ in the 
month of August and the highest rainfall was $333.609 \mathrm{~mm}$ in March. Looking at the lowest and the highest monthly maximum rainfalls for the two years, lowest monthly rainfall increased by $67.351 \mathrm{~mm}$ and the highest monthly rainfall decreased by $17.579 \mathrm{~mm}$.

However, the annual total rainfall received in 1956 and 2016 are $245.061 \mathrm{~mm}$ and $260.452 \mathrm{~mm}$ respectively as mentioned above. The numbers show that more rainfall was received in 2016, so it is safe to conclude that there was an increase in average yearly rainfall between 1956 and 2016. The numbers in Table 1 above are represented in Figure 2. Figure 2 also shows the trend analysis in rainfall for the two different years.

The dotted lines in both graph (a) and (b) show linear trendline for each of the two years. With a trendline equation of $y=-1.037 x+251.8$ for 1956 and $y=$ $-4.9194 x+292.43$ for 2016 , both show a declining trendline in rainfall from January to December. Although both linear trendlines are decreasing, the linear trendline for 2016 is steeper - which is going down compared to that of 1956. This shows that higher amount of the total annual rainfall was received in the first few months of the year in 2016 than in 1956. The blue dots in both graphs in Figure 2 show the rainfall for each of the months for each of the two years. It can be seen from the two graphs that the rainfall data for 1956 has a wider range than that of 2016, where they are closer together. After 70 years, the clear change observed is the increase in average monthly rainfall. In 1956, four months (May, June, July and October) recorded monthly average rainfall below $200 \mathrm{~mm}$; however, in 2016, none of them or the other eight months' average rainfall data recorded came below $200 \mathrm{~mm}$ with the month of May (which recorded the lowest in 1956) recording the highest among the five months with $254.75 \mathrm{~mm}$ of rain. This is a significant increase.

Although for 1956, the highest monthly average rainfall was above $350 \mathrm{~mm}$, while for 2016 it stays below $350 \mathrm{~mm}$; the total amount of rainfall recorded increased in 2016. The total amount of rainfall increased by $15.39 \mathrm{~mm}$ from 245.06 $\mathrm{mm}$ in 1956 to $260.45 \mathrm{~mm}$ in 2016. This is due to the increase in temperature trend caused by climate change.

\subsubsection{Analysis of Annual Rainfall Trend for All Years (1956-2016)}

The precipitation data provided by World Bank consisted of monthly rainfall data from January 1956 to December 2016. In order to come up with the average annual rainfall for each of the 60 years, 1956-2016, the monthly rainfalls were summed up and the total divided by twelve (representing twelve sets of data for the 12 months). All the units are in millimeters. The methodology used was Arithmetic Average Methodology shown in Table 2 below.

Used the above methodology, the average annual rainfall was calculated. Table 3 below shows the results, average annual rainfall, calculated using the above methodology. It also shows the minimum and the maximum rainfall in millimeters observed for each year in the 60 years, 1956-2016. 
Table 2. Arithmetic Average Methodology converted in order to calculate the annual average rainfall or precipitation $(P)$.

$$
\begin{aligned}
& \text { Arithmetic mean }(\bar{x}) \\
& =\quad \frac{x_{1}+x_{2}+x_{3}+x_{4}+x_{5}+x_{6}+\cdots+x_{n}}{n}=\frac{\sum_{i=1}^{n} x_{i}}{n} \\
& P_{a v}=\frac{P_{1}+P_{2}+P_{3}+P_{4}+P_{5}+P_{6}+\cdots+P_{n}}{n}=\frac{\sum_{i=1}^{n} P_{i}}{n} \\
& P_{a v} \quad=\quad \frac{P_{1}+P_{2}+P_{3}+P_{4}+P_{5}+P_{6}+P_{7}+P_{8}+P_{9}+P_{10}+P_{11}+P_{12}}{12}
\end{aligned}
$$

\begin{tabular}{|c|c|c|c|c|c|c|c|c|c|c|c|}
\hline Year & Mean & Minimum & Maximum & Year & Mean & Minimum & Maximum & Year & Mean & Minimum & Maximum \\
\hline 1956 & 245.06 & 136.47 & 351.19 & 1976 & 243.54 & 119.79 & 337.48 & 1996 & 278.82 & 138.24 & 398.96 \\
\hline 1957 & 256.42 & 158.08 & 413.65 & 1977 & 271.64 & 213.89 & 332.08 & 1997 & 252.24 & 172.36 & 368.83 \\
\hline 1958 & 243.08 & 102.72 & 334.09 & 1978 & 253.10 & 158.26 & 327.88 & 1998 & 268.57 & 186.87 & 377.88 \\
\hline 1959 & 234.32 & 165.23 & 374.91 & 1979 & 221.80 & 111.09 & 395.10 & 1999 & 274.88 & 182.86 & 418.80 \\
\hline 1960 & 271.03 & 170.02 & 393.48 & 1980 & 240.94 & 140.16 & 340.74 & 2000 & 250.17 & 141.92 & 325.56 \\
\hline 1961 & 272.20 & 216.85 & 370.95 & 1981 & 268.23 & 184.37 & 342.18 & 2001 & 258.87 & 170.82 & 352.81 \\
\hline 1962 & 268.49 & 174.43 & 371.72 & 1982 & 201.89 & 82.75 & 343.39 & 2002 & 263.42 & 203.82 & 333.61 \\
\hline 1963 & 235.06 & 145.33 & 317.53 & 1983 & 273.89 & 167.80 & 334.67 & 2003 & 251.50 & 203.82 & 333.61 \\
\hline 1964 & 273.34 & 157.35 & 382.23 & 1984 & 253.62 & 175.54 & 379.11 & 2004 & 256.18 & 203.82 & 333.61 \\
\hline 1965 & 219.27 & 79.42 & 388.01 & 1985 & 278.95 & 213.49 & 329.46 & 2005 & 255.32 & 142.15 & 341.30 \\
\hline 1966 & 268.52 & 138.21 & 453.26 & 1986 & 248.17 & 165.43 & 398.32 & 2006 & 251.98 & 165.74 & 333.61 \\
\hline 1967 & 264.49 & 172.68 & 363.09 & 1987 & 223.63 & 112.91 & 374.83 & 2007 & 265.49 & 155.02 & 375.12 \\
\hline 1968 & 232.71 & 118.47 & 350.52 & 1988 & 266.14 & 202.05 & 362.54 & 2008 & 265.05 & 174.25 & 351.64 \\
\hline 1969 & 262.85 & 191.72 & 345.35 & 1989 & 265.76 & 194.16 & 365.42 & 2009 & 275.56 & 203.82 & 418.85 \\
\hline 1970 & 293.40 & 188.40 & 419.12 & 1990 & 266.07 & 191.38 & 359.25 & 2010 & 297.76 & 181.87 & 461.59 \\
\hline 1971 & 280.67 & 175.70 & 334.14 & 1991 & 240.23 & 108.17 & 336.79 & 2011 & 263.47 & 170.02 & 354.29 \\
\hline 1972 & 212.78 & 65.16 & 374.90 & 1992 & 227.83 & 109.13 & 324.48 & 2012 & 274.63 & 189.96 & 373.84 \\
\hline 1973 & 297.41 & 177.06 & 435.92 & 1993 & 203.56 & 74.11 & 349.63 & 2013 & 259.63 & 203.82 & 333.61 \\
\hline 1974 & 243.77 & 120.97 & 369.68 & 1994 & 202.31 & 97.45 & 316.28 & 2014 & 267.24 & 152.87 & 484.31 \\
\hline \multirow[t]{2}{*}{1975} & 284.51 & 195.82 & 383.66 & 1995 & 255.87 & 144.73 & 361.30 & 2015 & 245.64 & 137.87 & 333.61 \\
\hline & & & & & & & & 2016 & 260.45 & 203.82 & 333.61 \\
\hline
\end{tabular}

Table 3. Descriptive rainfall statistics for the years 1956-2016.

The average yearly rainfall, together with the minimum and maximum rainfall for the years 1956-2016, displayed in Table 3 reveals that all yearly rainfall data fell within the range, $200 \mathrm{~mm}$ and $300 \mathrm{~mm}$. The average annual rainfall statistics given in Table 3 above are presented on the graph in Figure 3. The graph also shows the trend of rainfall in Papua New Guinea in the 60 years.

The trendline represented by the dotted black straight line is an increasing trend. The blue dots presentation the yearly average rainfall for each year and 


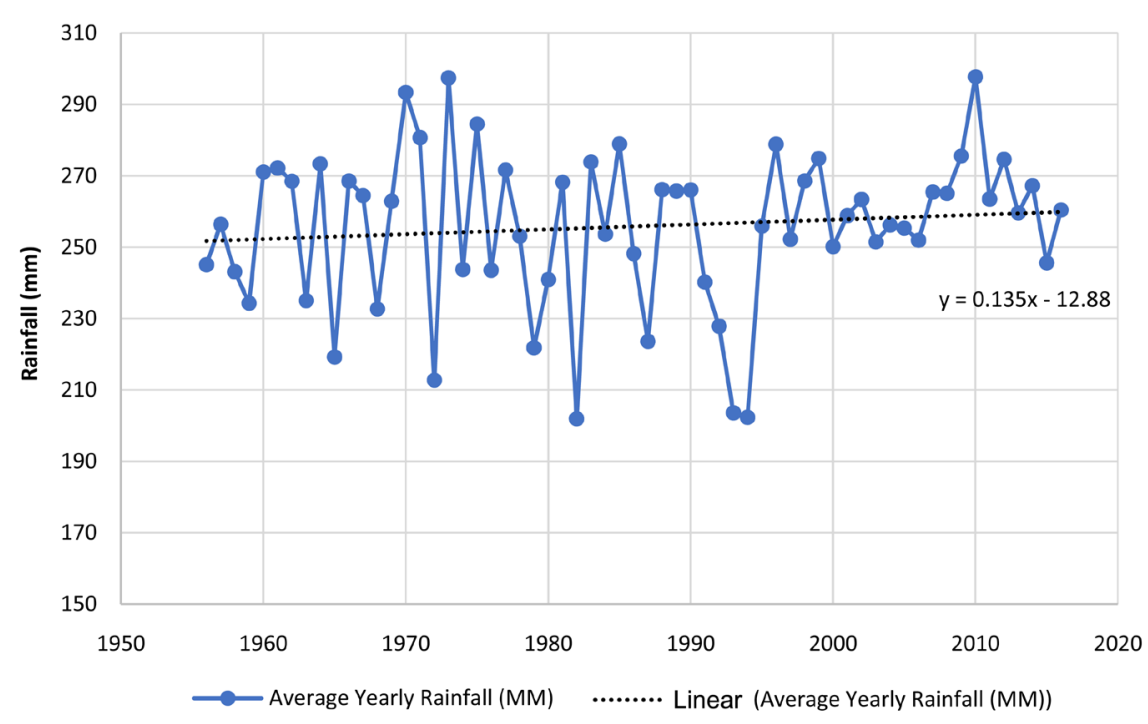

Figure 3. Rainfall trend for Papua New Guinea for the years 1956-2016.

the bold blue line represents the increase and decrease in rainfall from one year to the other. According to the graph above, the highest annual average rainfall was recorded in 2010 with $297.76 \mathrm{~mm}$, and the lowest annual average rainfall was recorded in 1982 with $201.89 \mathrm{~mm}$.

\subsection{Analysis of Temperature and It's Trendline}

\subsubsection{Analysis of Monthly Temperature for the Initial and the Final Year}

The average monthly temperature for the initial year (1956) and the final year year (2016) were selected to display to observe the difference in the temperature reading and the difference in temperature pattern in each of the months in the two years, after 60 years apart. Table 4 below shows the values and the subsequent Figure 4 presents two graphs ("a" and "b") representing the two years.

Table 4 shows the recorded monthly temperature for the initial year (1956) and the final year (2016) considered for this study. The two years were selected to observe the difference in the temperature reading in each of the months after 60 years apart, before looking into the other years that are in between them.

The average monthly temperature for the initial year (1956) and the final year year (2016) were selected to display among other years to see how temperature changed in each of the months after 70 years. Figure 4 below presents two graphs ("a" and "b") representing the two years.

Figure 4 shows the average monthly temperature for Papua New Guinea for the initial year and the final year considered for this study. The highest mean temperature reached between 1956 and 2016 was $25.70^{\circ} \mathrm{C}$ in 2016 while the lowest mean temperature reached between the same period was $24.38^{\circ} \mathrm{C}$ in 1965 . Generally, the mean temperature range is good. The average yearly temperature range doesn't go beyond $26^{\circ} \mathrm{C}$ and doesn't go below $24^{\circ} \mathrm{C}$.

After 70 years, a clear change observed is the increase in average monthly temperature. The highest monthly average temperature recorded in 1956 stands 


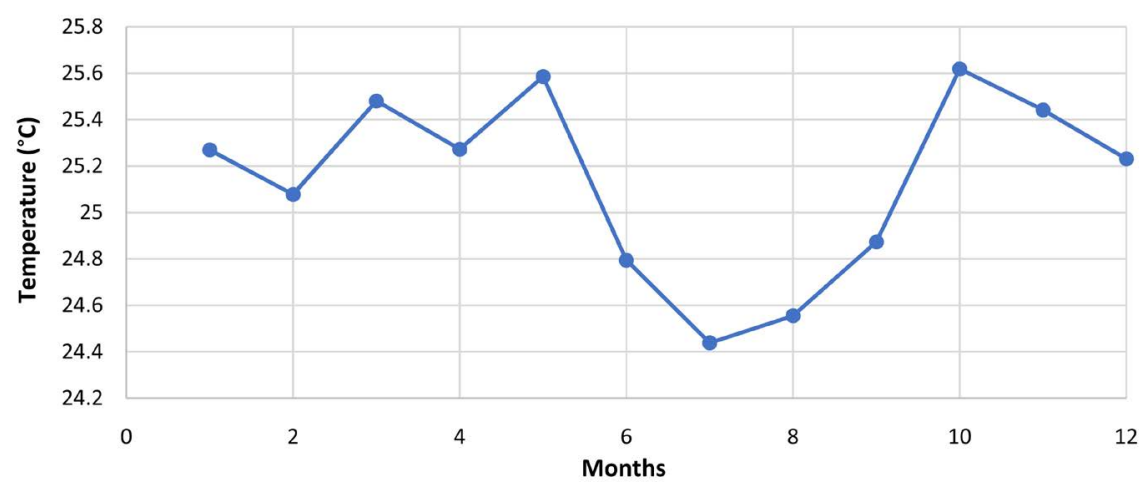

(a)

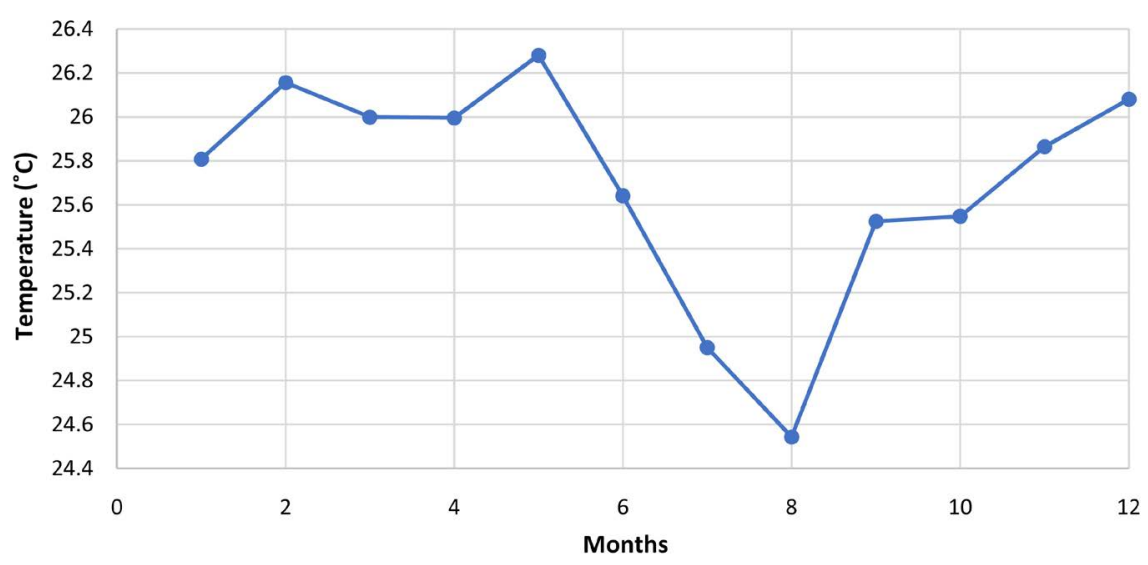

(b)

Figure 4. Average monthly temperature for Papua New Guinea (a) 1956 and (b) 2016.

Table 4. Monthly temperature statistics for the year 1956 and 2016.

\begin{tabular}{ccc}
\hline Months & Rainfall $(\mathrm{mm}), \mathbf{1 9 5 6}$ & Rainfall (mm), 2016 \\
\hline Jan & 25.27 & 25.81 \\
Feb & 25.08 & 26.16 \\
Mar & 25.48 & 26.00 \\
Apr & 25.27 & 26.00 \\
May & 25.59 & 26.28 \\
Jun & 24.79 & 25.64 \\
Jul & 24.44 & 24.95 \\
Aug & 24.56 & 24.54 \\
Sep & 24.87 & 25.52 \\
Oct & 25.62 & 25.55 \\
Nov & 25.44 & 25.86 \\
Dec & 25.23 & 26.08
\end{tabular}

at 25.61 degrees celsius, while the highest monthly average temperature recorded in 2016 stands at 26.28 degree celsius. 
3.2.2. Analysis of Annual Temperature Trend for All Years (1956-2016) The temperature data provided by World Bank consisted of monthly rainfall data from January 1956 to December 2016. In order to come up with the average annual temperature for each of the 60 years, 1956-2016, the monthly average temperatures were summed up and the total divided by twelve (representing twelve sets of data for the 12 months). All the units are in degree Celsius. The methodology used is arithmetic average methodology, the same one used for the calculation of trend for rainfall. The methodology is shown in Table 5 below.

Table 6 below shows the results, average annual temperature data, calculated using the above methodology. The table also displays the minimum and the maximum rainfall in degree Celsius recorded for each year, in 60 years, 1956-2016.

Table 5. Arithmetic average methodology converted in order to calculate the annual average temperature.

$\begin{array}{rlrl}\operatorname{Arithmetic} \text { mean }(\bar{x}) & = & \frac{x_{1}+x_{2}+x_{3}+x_{4}+x_{5}+x_{6}+\cdots+x_{n}}{n}=\frac{\sum_{i=1}^{n} x_{i}}{n} \\ & = & \frac{T_{1}+T_{2}+T_{3}+T_{4}+T_{5}+T_{6}+\cdots+T_{n}}{n}=\frac{\sum_{i=1}^{n} T_{i}}{n} \\ T_{a v} & =\frac{T_{1}+T_{2}+T_{3}+T_{4}+T_{5}+T_{6}+T_{7}+T_{8}+T_{9}+T_{10}+T_{11}+T_{12}}{12} \\ T_{a v} & & \end{array}$

Table 6. Descriptive temperature statistics for the years 1956-2016.

\begin{tabular}{|c|c|c|c|c|c|c|c|c|c|c|c|}
\hline Year & Mean & Minimum & Maximum & Year & Mean & Minimum & Maximum & Year & Mean & Minimum & Maximum \\
\hline 1956 & 25.14 & 25.62 & 24.44 & 1976 & 24.75 & 25.97 & 23.53 & 1996 & 25.03 & 25.76 & 23.56 \\
\hline 1957 & 24.92 & 25.61 & 24.16 & 1977 & 24.89 & 25.65 & 23.88 & 1997 & 24.77 & 25.84 & 23.49 \\
\hline 1958 & 25.17 & 25.71 & 24.02 & 1978 & 25.17 & 25.68 & 24.51 & 1998 & 25.66 & 26.40 & 24.92 \\
\hline 1959 & 24.87 & 25.86 & 23.89 & 1979 & 25.10 & 25.88 & 23.91 & 1999 & 25.01 & 25.60 & 23.99 \\
\hline 1960 & 24.77 & 25.45 & 23.89 & 1980 & 25.20 & 25.88 & 24.16 & 2000 & 24.93 & 25.91 & 23.67 \\
\hline 1961 & 24.64 & 25.51 & 23.72 & 1981 & 25.26 & 26.00 & 24.43 & 2001 & 25.16 & 26.12 & 23.73 \\
\hline 1962 & 24.92 & 25.83 & 23.91 & 1982 & 24.92 & 26.12 & 23.59 & 2002 & 25.29 & 26.08 & 24.07 \\
\hline 1963 & 24.76 & 25.64 & 23.40 & 1983 & 25.41 & 26.08 & 24.20 & 2003 & 25.41 & 26.32 & 24.20 \\
\hline 1964 & 24.97 & 25.53 & 24.18 & 1984 & 25.13 & 26.02 & 23.93 & 2004 & 25.19 & 26.25 & 23.67 \\
\hline 1965 & 24.38 & 25.25 & 22.70 & 1985 & 25.13 & 25.75 & 23.76 & 2005 & 25.22 & 26.06 & 23.93 \\
\hline 1966 & 24.69 & 25.18 & 23.53 & 1986 & 25.26 & 25.92 & 24.39 & 2006 & 25.08 & 25.66 & 24.15 \\
\hline 1967 & 24.60 & 25.43 & 23.74 & 1987 & 25.36 & 26.32 & 24.17 & 2007 & 25.09 & 25.84 & 23.75 \\
\hline 1968 & 24.72 & 25.38 & 24.12 & 1988 & 25.52 & 26.22 & 24.65 & 2008 & 25.00 & 26.14 & 24.03 \\
\hline 1969 & 24.95 & 25.62 & 24.11 & 1989 & 25.31 & 25.80 & 24.64 & 2009 & 25.32 & 25.82 & 24.55 \\
\hline 1970 & 25.01 & 25.49 & 23.93 & 1990 & 25.35 & 26.25 & 24.23 & 2010 & 25.64 & 25.98 & 24.86 \\
\hline 1971 & 24.97 & 25.80 & 23.94 & 1991 & 25.08 & 25.98 & 24.28 & 2011 & 25.02 & 25.94 & 24.14 \\
\hline 1972 & 24.62 & 25.54 & 23.59 & 1992 & 25.42 & 26.04 & 24.29 & 2012 & 25.17 & 25.93 & 24.30 \\
\hline 1973 & 25.22 & 25.82 & 24.15 & 1993 & 25.14 & 25.86 & 24.13 & 2013 & 25.34 & 25.90 & 24.38 \\
\hline 1974 & 24.97 & 25.65 & 23.86 & 1994 & 25.10 & 26.05 & 24.11 & 2014 & 25.27 & 26.08 & 24.04 \\
\hline \multirow[t]{2}{*}{1975} & 24.96 & 25.40 & 24.16 & 1995 & 25.09 & 26.15 & 24.03 & 2015 & 25.38 & 25.81 & 24.35 \\
\hline & & & & & & & & 2016 & 25.70 & 26.28 & 24.54 \\
\hline
\end{tabular}


The annual average temperature statistics together with the minimum and maximum temperature for the years 1956-2016, displayed in Table 6 reveals that all annual rainfall data fall within the range, 24.0 degree Celsius and 26.000 degree Celsius. The average annual mean temperature statistics given in Table 6 above are presented on the graph in Figure 5. The graph also shows the trend of temperature in Papua New Guinea in the 60 years.

The annual temperature trendline is represented by the dotted black straight line. The blue dots represent the annual average temperature for each year. And the bold blue line represents the increase and decrease in annual average temperature from one year to the other in the sixty years. According to the graph above, the highest annual average temperature was recorded in 2016 with 25.70 degrees, and the lowest annual average temperature was 24.34 degrees recorded in 1965.

A research found that there were increased temperatures in the Tropical Pacific Region, region where Papua New Guinea is located. Correlations between mean temperature and the frequency of extreme temperatures were strongest in the tropical Pacific Ocean from French Polynesia to Papua New Guinea, Malaysia, the Philippines, Thailand and southern Japan (Griffiths et al., 2005). Obviously, the increase in the trend of rainfall in Papua New Guinea is a result of the increase in temperature. The results in this work with an increased trend in both rainfall and temperature coincide well with the above research.

\subsection{Projection of Rainfall and Temperature 2017-2047}

Apart from the annual average rainfall and temperature trend observations for the sixty years, the monthly average rainfall and monthly average temperature trend observation were also done. These gave reflection of how the two recorded parameters looked like when each one of them increased or decreased from one month to another in each year from January 1956 to December 2016. The

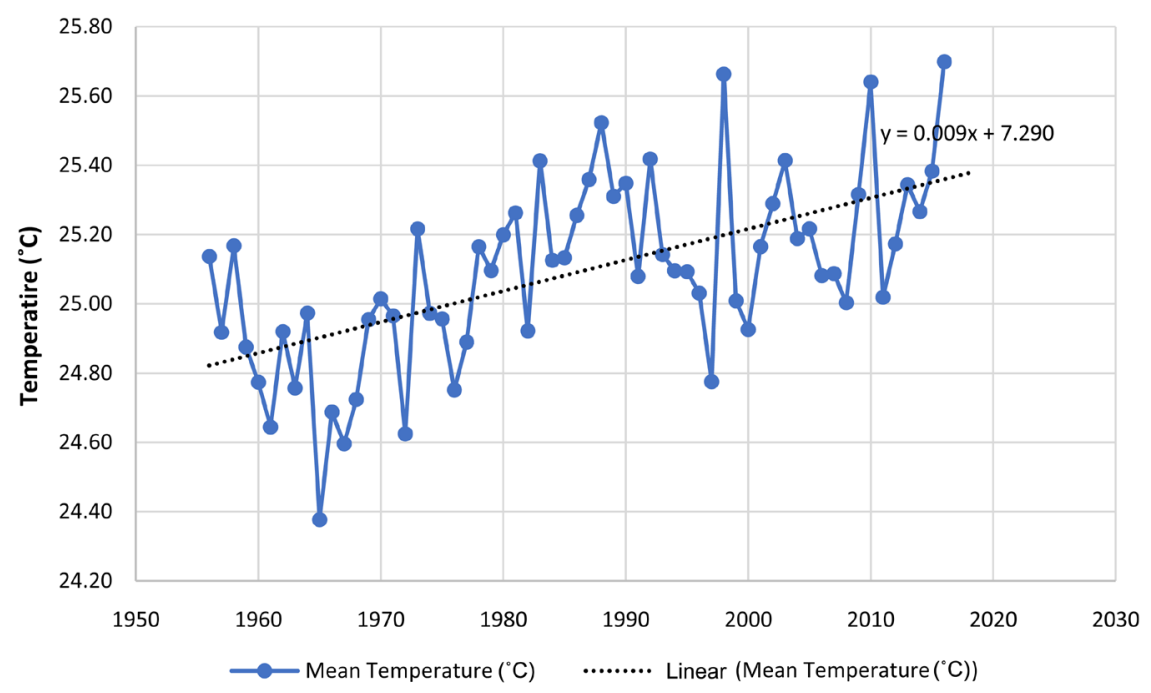

Figure 5. Temperature trend for Papua New Guinea, 1956-2016. 
projection of rainfall and temperature for the next 30 years was made using monthly average rainfall data. The projections rainfall and temperature and are shown in Figure 7 and Figure 9 respectively.

\subsubsection{Rainfall Projection}

The monthly average rainfall trend observed for 1956 to 2016 is shown in Figure 6.

Figure 6 shows the monthly rainfall pattern for Papua New Guinea. From Figure 6, it can be seen that there is an increasing trend in rainfall in the sixty years. The equation extracted from the above trendline is; $y=0.0093 x+252.38$. Using this equation, a project of 30 years was made. Thirty years were decided because sixty years of data is sufficient to predict and project the period's rainfall trendline. To come up with the projected temperature for each of the months in those 30 years, Equation I ( $" y=a+b x$ ”) in Table 7 was been used. Following data are substituted into the above equation I:

\section{Projected Rainfall $\left(P_{R}\right)$}

$$
\begin{aligned}
& y=a+b x \\
& P_{T}=\text { intercept }+ \text { slope } \times \text { rainfall data } \\
& P_{T}=7.29040829+0.008962781 \text { (monthly rainfall data) }
\end{aligned}
$$

After the projected rainfall for 2017-2047 were calculated, projections were made. The projected monthly average rainfall for Papua New Guinea is shown in Figure 7.

Figure 7 shows 60 years of monthly rainfall in millimeters recorded in Papua New Guinea from January 1956 to December 2016. The bold blue line shows the

Table 7. Equations used in the rainfall and temperature projections.

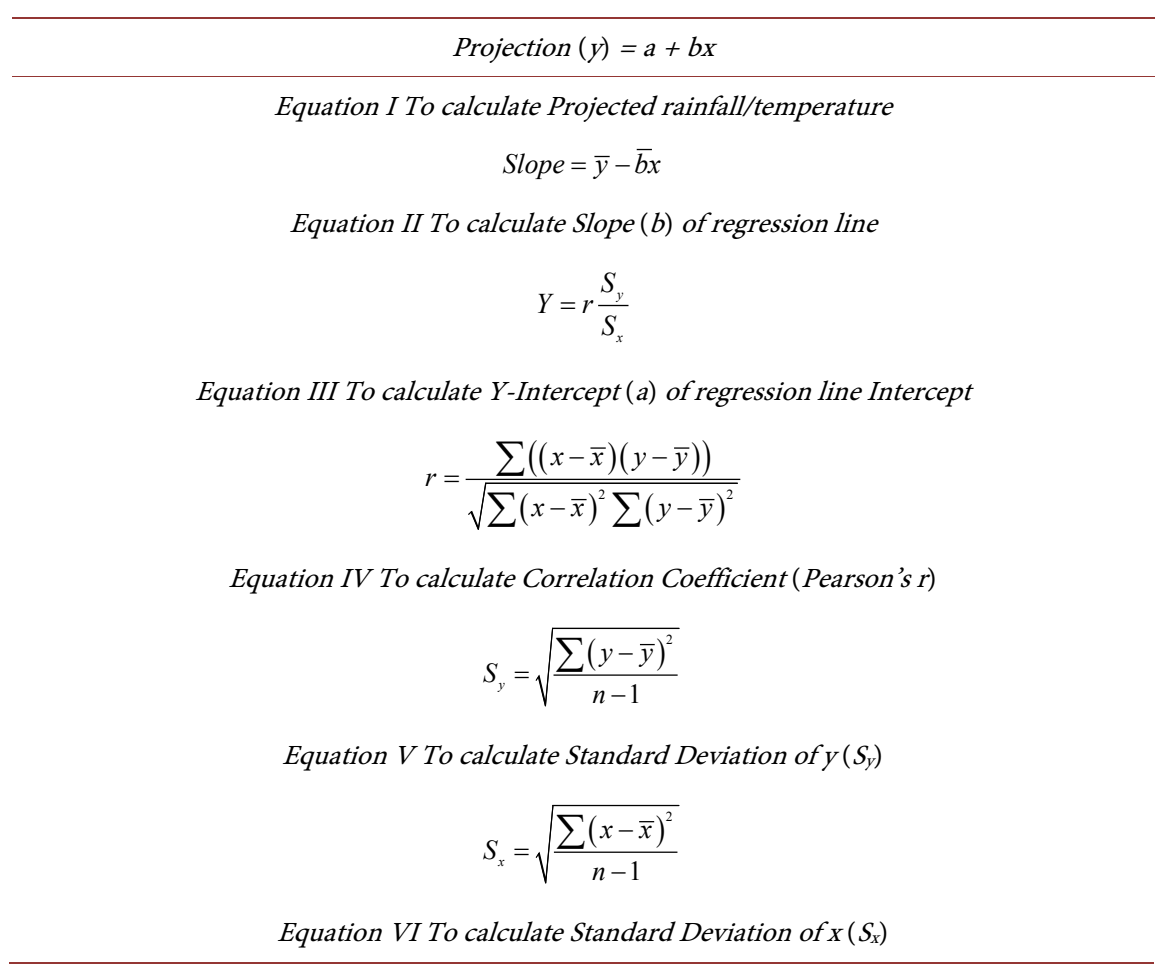




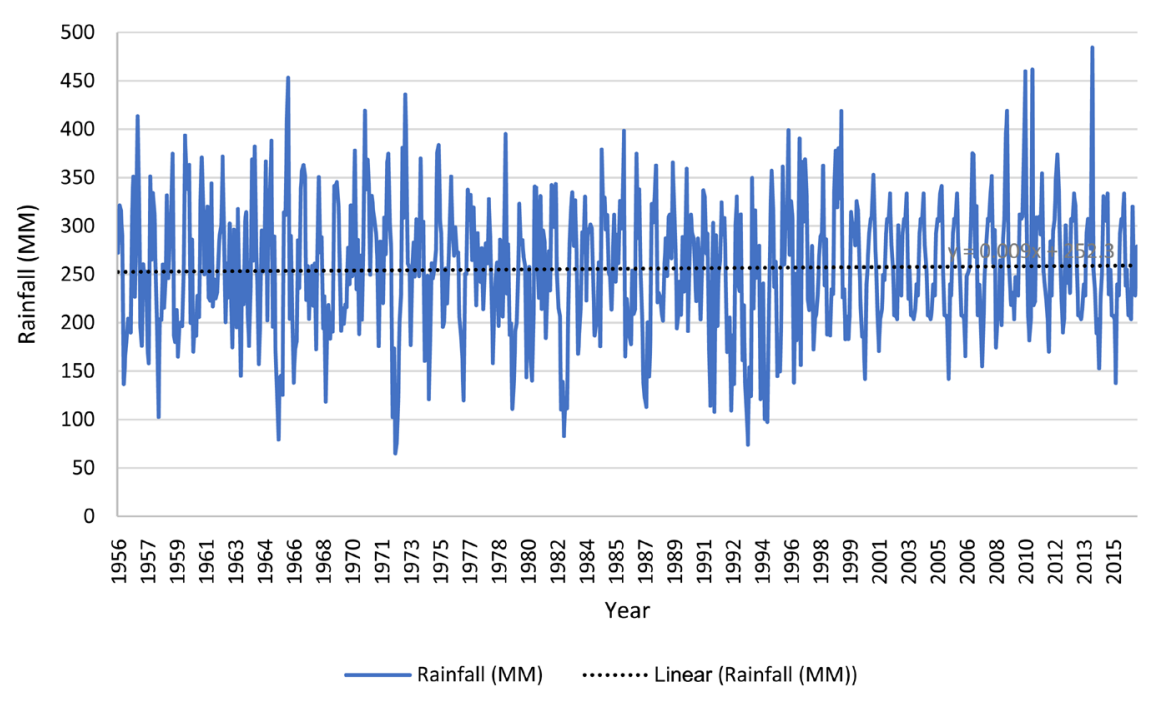

Figure 6. Monthly average rainfall (MM) for Papua New Guinea from January, 1956-December, 2016.

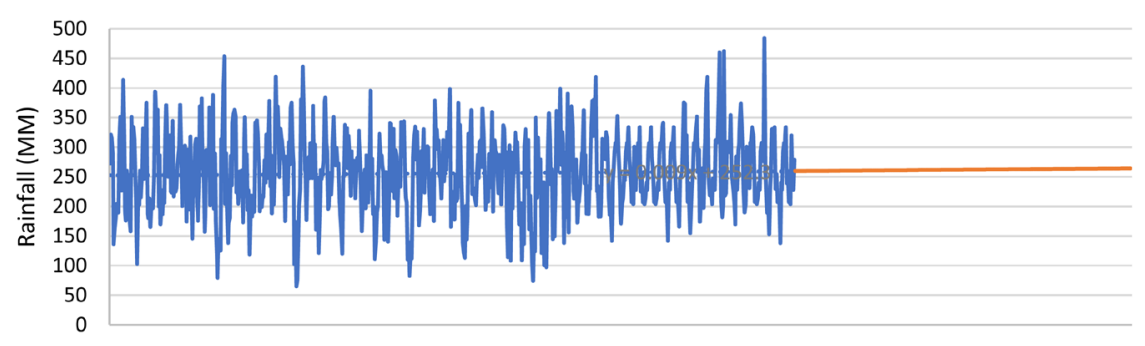

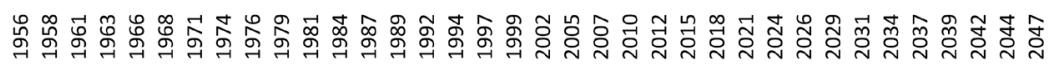

Rainfall (MM) ….... Projected Trend (Rainfall (MM)) …... Linear (Rainfall (MM))

Figure 7. Showing projected trend for average monthly rainfall (in red) for Papua New Guinea, 2017-2047.

increase and decrease in rainfall. It reveals that Papua New Guinea recorded the lowest average monthly rainfall of $65.1629 \mathrm{~mm}$ on the month of August in 1972. The country's highest amount of monthly rainfall of $484.306 \mathrm{~mm}$ was recorded on the month of April in 2014.

The dotted blue linear trendline shows the increasing trend in rainfall in the 60 years. The bold red line towards the end projects trendline from January 2017 to December 2047. The projection shows and increases in rainfall for the country.

\subsubsection{Temperature Projection}

The monthly average temperature trend observed for 1956 to 2016 is shown in Figure 8.

Figure 8 shows the monthly average temperature pattern for Papua New Guinea. It is seen that there is an increasing trend in temperature in the sixty years. The equation extracted from the trendline above is; $y=0.0007 x+24.818$. Using this equation, a project of 30 years was made. 


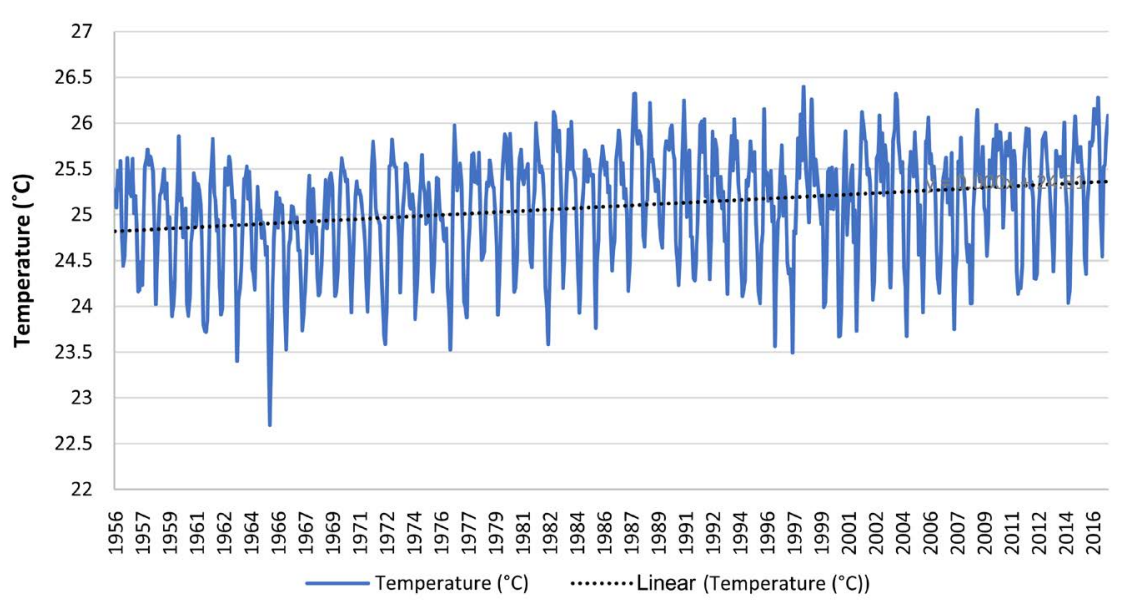

Figure 8. Monthly average temperature $\left({ }^{\circ} \mathrm{C}\right)$ for Papua New Guinea from January, 1956-December, 2016.

Thirty years were decided because sixty years of data is sufficient to predict and project the period's temperature trendline. To come up with the projected temperature for each of the months in those 30 years Equation I ( $" y=a+b x$ ”) in Table 7 has been used. Following data are substituted into the above equation I:

\section{Projected Temperature $\left(P_{T}\right)$}

$$
\begin{aligned}
& y=a+b x \\
& P_{T}=\text { intercept }+ \text { slope } \times \text { temperature data } \\
& P_{T}=7.29040829+0.008962781 \text { (temperature data) }
\end{aligned}
$$

After the projected rainfall for 2017-2047 were calculated, projections were made. The projection for monthly average temperature for Papua New Guinea is shown in Figure 9.

Figure 9 shows the 60-year monthly temperature change for Papua New Guinea between January 1956 to December 2016 and the projection between 2017-2047. The increase and decrease are shown by bold blue line. It reveals that Papua New Guinea recorded the lowest monthly average temperature of $22.7034^{\circ} \mathrm{C}$ on the month of July in 1965 . The country recorded the highest monthly average temperature of $26.399^{\circ} \mathrm{C}$ on the month of April in 1998.

The thin straight dotted blue linear trendline shows the increasing trend in temperature in the 60 years. The bold red linear trendline shows the projection in temperature from January 2017 to December 2047. The projection reveals an increase in temperature in the next 30 years for the country. Generally, Papua New Guinea is already warm, being located in the tropics, just 6 degrees south of the equator (Tsuchiya, 1991) (Kawabe, Kashino, \& Kuroda, 2008). It has only two seasons, wet and dry, and so, it does not experience summer or winter. Although the seasons may not change to summer or winter because of the country's position, near the equator, extreme changes in temperatures may affect plants and animals including human beings. An increase in temperature, rainfall, and humidity may cause a proliferation of the malaria-carrying mosquitoes at higher altitudes, resulting in an increase in malaria transmission (Fernando, 


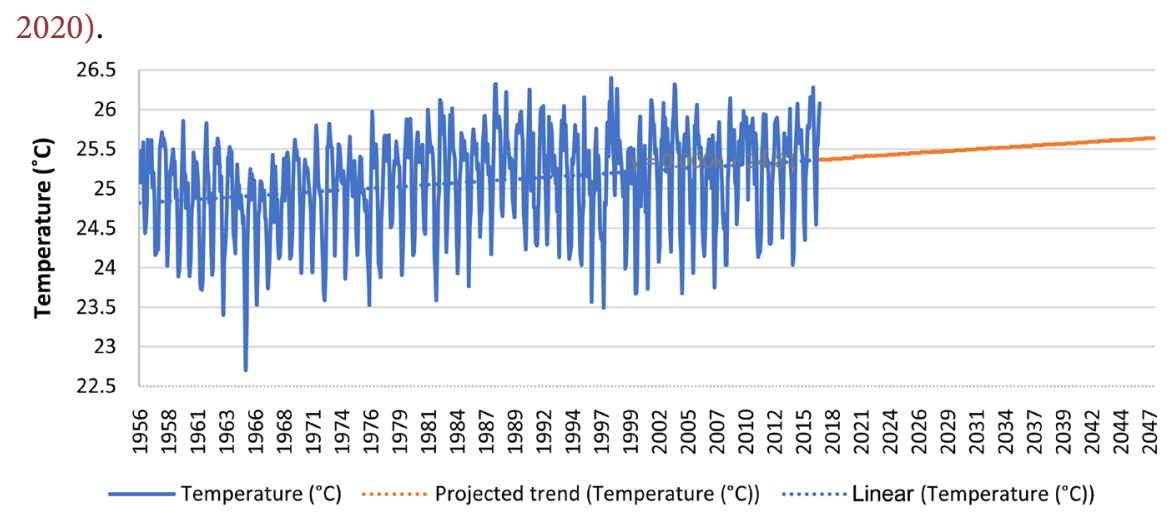

Figure 9. Showing projected trend for average monthly temperature (in red) for Papua New Guinea 2017-2047.

According to Figure 8 and Figure 9, Papua New Guinea recorded very low temperature in 1792 and 1997. This correlated well with events in the country where the Highlands region was extremely affected by drought in 1972 and 1997 (Barr, 2019; Tadesse, Brown, \& Hayes, 2005; White \& Walcott, 2009). Researchers have found that there is correlation between rainfall and temperature. The spatial pattern of surface air temperature change is correlated to the changes in moderate precipitation ( $\mathrm{Yu} \& \mathrm{Li}, 2012$ ). The increased trend in both of the parament agrees with this.

\section{Discussion}

Over the period of study period 1956 to 2016, the study found that the climatic factors, rainfall, and temperature pattern in Papua New Guinea has been changing. The general linear model analysis was used to investigate the trend in both rainfall and temperature and to predict the future trends. It was found that there is an increasing trend in rainfall and temperature (Figure 6 and Figure 8). Projections (Figure 7 and Figure 9) reveal a future increase in rainfall and temperature into the future. The critical impact areas of increase in precipitation, high temperature, and rise in sea level are on terrestrial and aquatic resources, civic infrastructure, population and agriculture (Michael, 2019).

Rainfall in Papua New Guinea is increasing in April, May June and July; which were the months with lowest rainfall. And the month of September, October, November and December which experiences the highest rainfall in the 1950s is now experiencing a decline. For examples, in 1956 the month of December received $351.19 \mathrm{~mm}$, but received $278.85 \mathrm{~mm}$ in 2016. This amount $(278.85 \mathrm{~mm})$ of rainfall received in December 2016 is lower than the amount received in January, February, March, and September; months which received lower rainfall than December did in 1956. The highest rainy month is where the rain intensity is high and flooding could result. The projection of rainfall for Papua New Guinea revealed that rainfall was trending upward with a linear model equation: Rainfall $=0.0093 x+252.38$. The increased trend in rainfall suggests that there is an increase in evaporation and transpiration taking place. 
Factors such as temperature, humidity, evaporation, and vegetation contribute to the amount of rainfall recorded in a locality (Issahaku, Campion, \& Edziyie, 2016). Therefore, as long as temperature change continues to take place, they'll be a change in rainfall in Papua New Guinea.

There is change in temperature in Papua New Guinea. Although it does not come down to zero or go up to 40 or 50 as in other countries, the change is clear in the analysis made in this study There is an increasing trend in temperature for the country. The highly non-linear nature of the relationship between changes in mean temperature and the corresponding changes in extreme temperature events is well known, relatively small alterations in the mean state can result in a large change in the probabilities of extreme events (Griffiths et al., 2005). In this study, there is an increasing trend in temperature (see Figure 8). Also, it is clear from the projected trendline (Figure 9) that temperatures in Papua New Guinea would continue to increase into the future.

There is a huge amount of logging going on in Papua New Guinea that is decreasing the number of trees (CCDA, 2017). As trees are decreased, $\mathrm{CO}_{2}$ will continue to increase which will continue to increase the temperature. As a result, carbon absorption is decreasing and carbon emission is increasing (CCDA, 2018). This would continue to increase, as emissions of carbon-dioxide into the air has a direct relationship with the increase in temperature (Legates, 2012).

If this increasing trend in the two parameters continues, a lot is at risk for Papua New Guinea. The country is home to the third largest tropical rainforest in the world (CCDA, 2014). It has the $6 \%$ of the world's biodiversity on less than $1 \%$ of the land (OCCD, 2015). Also, the country is part of the Coral Triangle which has more coral reef fish diversity than anywhere else in the world: $37 \%$ (2228) of the world's coral reef fish species (6000), and 56\% of the coral reef fishes in the Indo-Pacific region (4050). 8\% (235 species) of the coral reef fishes in the Coral Triangle are endemic or locally restricted species (WWF, 2015) (Drew, Amatangelo, \& Hufbauer, 2015). To save these and other organisms which depend on the land and seas in Papua New Guinea, the current increased trend in rainfall and temperature needs to be addressed to decrease or stabilize the parameters.

\section{Conclusion}

In this study, the assessment of trend and variations in rainfall and temperature in Papua New Guinea between 1956 and 2016 (60 years) was done. Also, projection of the trends from 2017 to 2047 (30 years) was done. In sixty years, the trend in rainfall and temperature increased for the country. This shows that there has been a change in the climatic condition for Papua New Guinea where the place was getting warmer due to the increasing in temperature. The projections (see Figure 7 and Figure 9) showed an increasing trend in the monthly average rainfall and temperature from January 2017 to December 1947. The two parameters, rainfall and temperature, are projected to increase with a linear regression functions of $y=0.0093 x+252.38$ and $y=0.0007 x+24.818$ respectively. 
If nothing is done to combat the current rate of climatic changes experienced in the country, the increasing trend in rainfall and temperature would continue.

The increase in temperature and rainfall is not healthy for both plants and animals including humans. This would introduce new diseases. An increase in temperature, rainfall, and humidity may cause a proliferation of the malaria-carrying mosquitoes at higher altitudes, resulting in an increase in malaria transmission. Plants and animals which live in both the sea and on land which cannot adapt to changes could eventually be at the risk of dying out. It is clear that the increasing trends in both rainfall and temperature would not see any decrease in the near future unless something is done. And, this calls for immediate actions as the issue needs to be addressed in time. Therefore, it is recommended that the government of Papua New Guinea consider incorporating climate change policies into their development plans.

\section{Acknowledgements}

The authors of this paper wish to thank the World Bank, Washington DC, for making rainfall and temperature data available to us for use. A special thanks to Emmanuel B. Greene for making this possible.

\section{Conflicts of Interest}

The authors declare no conflicts of interest regarding the publication of this paper.

\section{References}

Barr, J. (2019). Reducing the Impact of Environmental Emergencies through Early Warning and Preparedness. Tokyo.

Cámara-Leret, R., Raes, N., Roehrdanz, P., de Fretes, Y., Heatubun, C. D., Roeble, L., Schuiteman, A., van Welzen, P. C., \& Hannah, L. (2019). Climate Change Threatens New Guinea's Biocultural Heritage. Science Advances, 5, eaaz1455.

https://doi.org/10.1126/sciadv.aaz1455

CCDA (2014). National Climate Compatible Development Management Policy. Papua New Guinea.

CCDA (2017). Papua New Guinea's National REDD+ Forest Reference Level. Port Moresby.

CCDA (2018). Papua New Guinea's First Biennial Update Report to the United Nations Framework Convention on Climate Change. Port Moresby: Climate Change and Development Authority.

CSIRO (2015). Australian National Outlook 2015.

Drew, J. A., Amatangelo, K. L., \& Hufbauer, R. A. (2015). Quantifying the Human Impacts on Papua New Guinea Reef Fish Communities across Space and Time. PLoS ONE, 10, e0140682. https://doi.org/10.1371/journal.pone.0140682

Fernando, S. D. (2020). Climate Change and Malaria-A Complex Relationship. United Nations.

Griffiths, G. M., Chambers, L. E., Haylock, M. R., Manton, M. J., Nicholls, N., Baek, H. J., Choi, Y., Della-Marta, P. M., Gosai, A., Iga, N., Lata, R., Laurent, V., Maitrepierre, L., 
Nakamigawa, H., Ouprasitwong, N., Solofa, D., Tahani, L., Thuy, D. T., Tibig, L., Trewin, B., Vediapan, K., \& Zhai, P. (2005). Change in Mean Temperature as a Predictor of Extreme Temperature Change in the Asia-Pacific Region. International Journal of Climatology, 25, 1301-1330. https://doi.org/10.1002/joc.1194

IOM (2008). Migration and Climate Change. Geneva.

Issahaku, A.-R., Campion, B. B., \& Edziyie, R. (2016). Rainfall and Temperature Changes and Variability in the Upper East Region of Ghana. Earth and Space Science, 3, 284-294. https://doi.org/10.1002/2016EA000161

Kaluwin, C., Inape, K., \& Virobo, M. (2016). Chapter 11 Papua New Guinea. In Climate Change in the Pacific: Scientific Assessment and New Research. Volume 2: Country Reports. Chapter 11: Papua New Guinea (pp. 169-184). Canberra: National Library of Australia.

Kawabe, M., Kashino, Y., \& Kuroda, Y. (2008). Variability and Linkages of New Guinea Coastal Undercurrent and Lower Equatorial Intermediate Current. Journal of Physical Oceanography, 38, 1780-1793.

Legates, D. (2012). Carbon Dioxide and Air Temperature: Who Leads and Who Follows? (pp. 1-9).

Mann, T., \& Westphal, H. (2016). Multi-Decadal Shoreline Changes on Takú Atoll, Papua New Guinea: Observational Evidence of Early Reef Island Recovery after the Impact of Storm Waves. Geomorphology, 257, 75-84.

https://doi.org/10.1016/j.geomorph.2015.12.028

Michael, P. S. (2019). Current Evidence and Future Projections: A Comparative Analysis of the Impacts of Climate Change on Critical Climate-Sensitive Areas of Papua New Guinea. SAINS TANAH-Journal of Soil Science and Agroclimatology, 16, 229. https://doi.org/10.20961/stjssa.v16i2.35712

OCCD (2014). Papua New Guinea Second National Communication to the United Nations Framework Convention on Climate Change. Port Moresby.

OCCD (2015). Intended Nationally Determined Contribution (INDC) under the United Nations Framework Convention on Climate Change. Port Moresby.

Panda, A., \& Sahu, N. (2019). Trend Analysis of Seasonal Rainfall and Temperature Pattern in Kalahandi, Bolangir and Koraput Districts of Odisha, India. Atmospheric Science Letters, 20, e932. https://doi.org/10.1002/asl.932

Seth, W. (2013). Increases in Rainfall Extremes Linked to Global Warming. The Conversation.

Sungkuk, K., \& Ibrahim, A. (2015). Climate Change in Papua New Guinea. United Nations Education Science and Cultural Organisation.

http://www.climatefrontlines.org/blog/climate-change-papua-new-guinea

Tadesse, T., Brown, J. F., \& Hayes, M. J. (2005). A New Approach for Predicting Drought-Related Vegetation Stress: Integrating Satellite, Climate, and Biophysical Data over the U.S. Central Plains. ISPRS Journal of Photogrammetry and Remote Sensing, 59, 244-253. https://doi.org/10.1016/j.isprsjprs.2005.02.003

Tsuchiya, M. (1991). Flow Path of the Antarctic Intermediate Water in the Western Equatorial South Pacific Ocean. Deep Sea Research Part A. Oceanographic Research Papers, 38, S273-S279. https://doi.org/10.1016/S0198-0149(12)80013-6

Weldegerima, T. M., Zeleke, T. T., Birhanu, B. S., Zaitchik, B. F., \& Fetene, Z. A. (2018). Analysis of Rainfall Trends and Its Relationship with SST Signals in the Lake Tana Basin, Ethiopia. Advances in Meteorology, 2018, Article ID: 5869010.

https://doi.org/10.1155/2018/5869010 
White, D. H., \& Walcott, J. J. (2009). The Role of Seasonal Indices in Monitoring and Assessing Agricultural and Other Droughts: A Review. Crop and Pasture Science, 60, 599-616. https://doi.org/10.1071/CP08378

WHO (2015). WHO Calls for Urgent Action to Protect Health from Climate Change-Sign the Call. WHO Climate Ch.

https://www.who.int/news/item/06-10-2015-who-calls-for-urgent-action-to-protect-he alth-from-climate-change-sign-the-call

WWF (2015). Coral Triangle Facts. WWF Global.

Yu, R. C., \& Li, J. (2012). Hourly Rainfall Changes in Response to Surface Air Temperature over Eastern Contiguous China. Journal of Climate, 25, 6851-6861. 